\title{
Cigarette Smoke Analysis by Computer - GLC*
}

\author{
by J. F. Graham \\ Cigarette Components Limited, Research and Instrument Department, \\ Alperton, Wembley, England
}

\section{INTRODUCTION}

A previous communication ( $I$ ) described the functions and operation of a GLC device for cigarette smoke analysis. The present paper describes the use of a computer for measurement of the amounts of smoke constituents separated in this way, and reports some of the results obtained.

The Fraction Trapping and Transfer Device (FTTD), Fig. 1, produces a two-stage separation of the smoke "semi-volatiles" mixture. A series of fractions trapped from the separation on the first column are further separated on a secondary column, of different polarity, and it is this secondary separation on which the measurements must be made. Repeated primary runs, with choice of different fractions from each primary separation, permit the "semi-volatiles" sample to be divided into up to 30 defined fractions. These yield an average of 25 peaks each on the second column: thus a large number of peak area measurements are required for each smoke analysis.

Manual methods were not considered to be suitable, in view of the number of peak area measurements involved (up to 350 /day). The use of an electronic integrator was a possible solution, but the limitations of these instruments in peak sensing and baseline drift correction (2),

Figure 1. The FTTD sysiem.

GLC (1) is shown on the right, the FTTD in the centre, GLC (2) and the digitiser on the left.

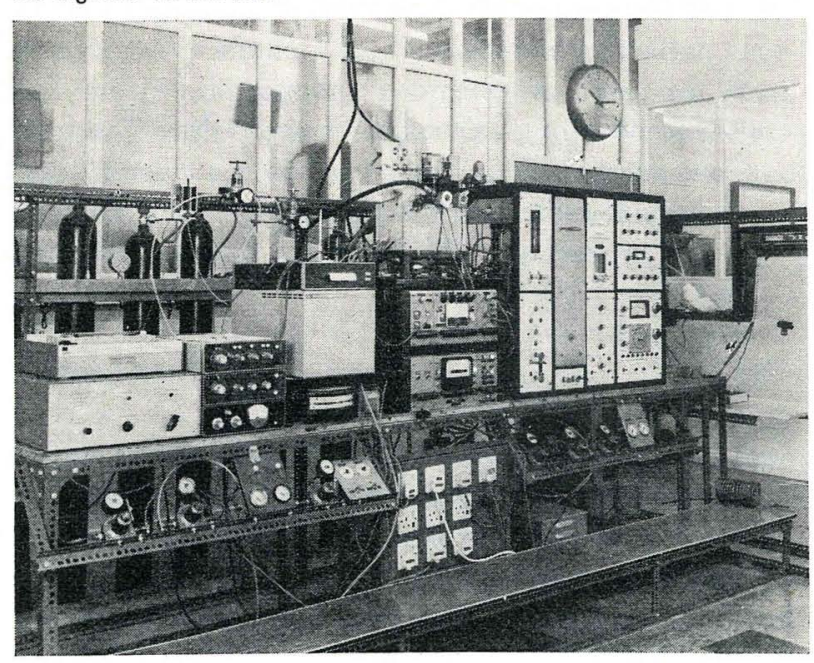

* Received for publication: 12th February, 1970. and also the necessity of further calculations on the area measurements, indicated the use of computer processing as a more suitable method.

There have been many reports of the use of computers for GLC measurements in the last few years, the systems described being of two main types: for on-line, and off-line application. An on-line computer is usually used where large numbers of short analyses are being done, and the results are required immediately, e. g. for process control purposes (3). For research analyses of the type being considered here, the requirement of speed is less important, and an on-line system is not necessary. Use of an off-line system has the advantage, in this case, that the GLC data can be recorded in a suitable form as it is produced, and computer time can be used subsequently, as required, to process the data. In this way, the computer costs can be reduced to a minimum.

The system to be described records GLC data in digital form on punched paper tape; results are obtained by a computer from each analysis tape, using a program developed for this work, the computer time being purchased as required from a Computer Bureau.

\section{DATA CONVERSION}

The analogue voltage output of the chromatograph must be converted to digital form before it can be processed by the computer. Of the various methods available for doing this, it was decided that shaft encoding (4), although involving less initial cost than other methods, had the disadvantages that recorder errors were superimposed on the data, and that off-scale peaks on the recorder could not be measured, thus requiring an automatic attenuator. The use of a data logger of the digital voltmeter type $(4,5)$ was also rejected, because of the very short sampling intervals used. Individual voltage samples can be seriously affected by electrical noise, and as the computer has to reconstruct the GLC data by fitting a curve through the digital sample values, filtering or smoothing is normally required before this can be done.

The best system appeared to be that described by Johnson (6), in which an integrating digitiser is used. This samples the output of the chromatograph at regular time intervals and integrates the output voltage against 
time throughout the interval period. At the end of each interval, the counters are rapidly reset to zero, and another integral count is immediately started. The numbers built up in this way are recorded in turn on a computer-compatible medium: Johnson used magnetic tape, but we use 7 -hole paper tape, on which the data is punched as coded 5-digit values.

Any changes in the voltage output of the chromatograph are thus translated into changes in value of the numbers punched. This system has the advantage that the time intervals used can be considerably longer than the cycle time of most electrical noise, and any noise pulses will thus be averaged out, and will not affect the data. Also, the digital output contains virtually all of the GLC information as area vs. time, and no curve reconstruction is required of the computer; all that has to be done is to find the correct parts of the data to be assigned to each peak area.

The digitiser used is the Infotronics CRS-30, working in conjunction with an Addo 5 tape punch. The digitiser is connected to the output of the FTTD secondary chromatograph, and a separate recorder output is provided from the CRS-30, to avoid recorder impedance variations affecting the chromatograph output. Fig. 2 shows a block diagram of the FTTD-computer system.

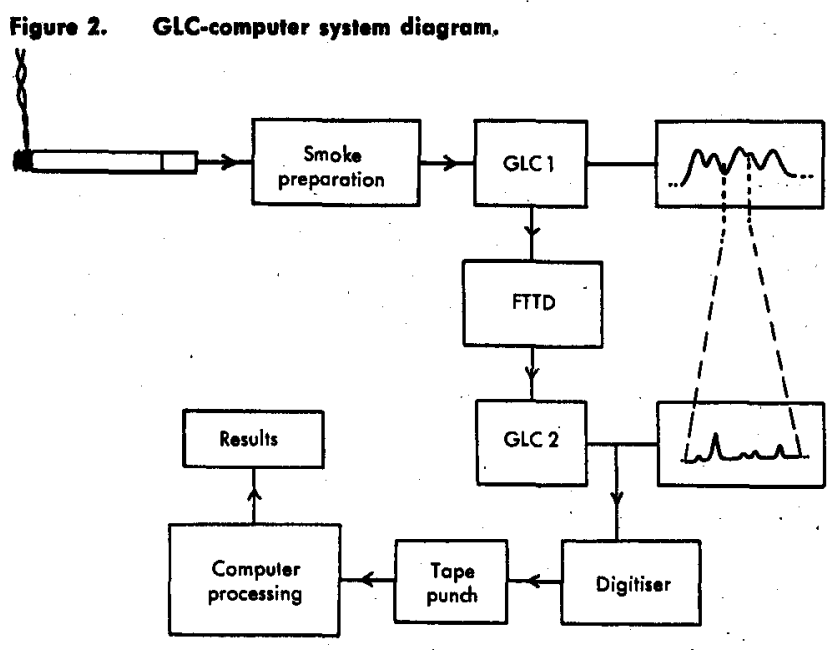

The sampling period normally used is 2 seconds, which gives approx. 5-15 digitisations per peak, with the secondary chromatograms obtained on the $10^{\circ} \times 1 / 8$ " packed column. This has been found to allow adequate resolution of inflection points by the computer. The period can be set between 4 seconds and the maximum punching rate of the Addo 5 (about 1 /second). Increased rates, down to $0.3 \mathrm{sec} /$ interval, can be obtained using a faster punch.

The count rate of the CRS-30 is $2000 / \mathrm{mV}$, so that using the $5 \mathrm{mV}$ output of the PV 4018 chromatograph, full scale deflection is equivalent to a count of 10,000 per digitisation period. The resolution is \pm 1 count in 99,999 , i. e. $0.001 \%$ FSD. As the linear input range of the digitiser is $0-50 \mathrm{mV}$, it would be capable of accepting any off-scale peaks up to $10 \times$ FSD: this is, however, beyond the saturation limit of the chromatograph amplifier, and tests have shown that (depending on the attenuation used) saturation occurs at $15-20 \mathrm{mV}$ output (when using the $5 \mathrm{mV}$ output terminals). This means that, within any one fraction we can deal with peaks of height range at least 1-300; and by choosing suitable attenuation settings to be used for particular fractions, this provides measurements on quite a comprehensive range of SV constituents, without the need for attenuation changes during any fraction. Thus the added complexity of attenuation switching, in the data collection system and in the computer program (5) can be avoided.

\section{COMPUTER PROGRAM DESIGN}

The computer program was designed to allocate peak areas in a similar way to that which would be used by a human operator: certain basic assumptions were made about the chromatograms to be measured, and rules for measurement were laid down, which could be used in all cases. The program was then written as a series of routines, so that alterations and improvements could be made with little difficulty, when required. The program language is Fortran $V$, an extended version of Fortran, developed for use with the Atlas Computer (7).

The chromatograms are mainly temperature programmed runs lasting 10-20 minutes. Peak widths are normally $10-30$ seconds; in some cases up to 60 seconds. Baseline drift is present in many of the fraction chromatograms, but is not very serious, and the maximum rate of drift is thus considerably less than the lowest rate of increase of a significant peak. A significant peak was defined as one which would clearly be visible on a normal chart recorder trace, at the attenuations used. This would include substances present to the extent of about $0.2 \mu \mathrm{g} / \mathrm{cigarette}$ or more, for most fractions.

It was decided that the "rules" to be followed in the measurements should be in the form of program instructions operating through variable parameters, and that the parameters would be assigned by the operator, for each fraction processed. Experiments with data tapes, using different parameter values on the same data, allowed the choice of parameters which would give the desired peak area measurements, corrected for baseline drift in a satisfactory way. These experiments showed that a single set of parameters could be used for all of the SV fractions, once the optimum values had been decided: however, the possibility of choice of parameter values makes the program more flexible, in that it can be "adjusted" to deal with chromatograms having different characteristics from those mentioned above.

The program has four main parts: input, area measurement, internal standard correction, and output. A flow chart of the program is shown in Fig. 3.

\section{Input}

The punched tape presented to the computer contains digital data from 15-20 fractions normally; the result of one day's GLC output. Each set of fraction data is preceded by a set of identification data, punched manually from a keyboard-connected to the Addo 5. 
Figure 3. Computar program how chart.

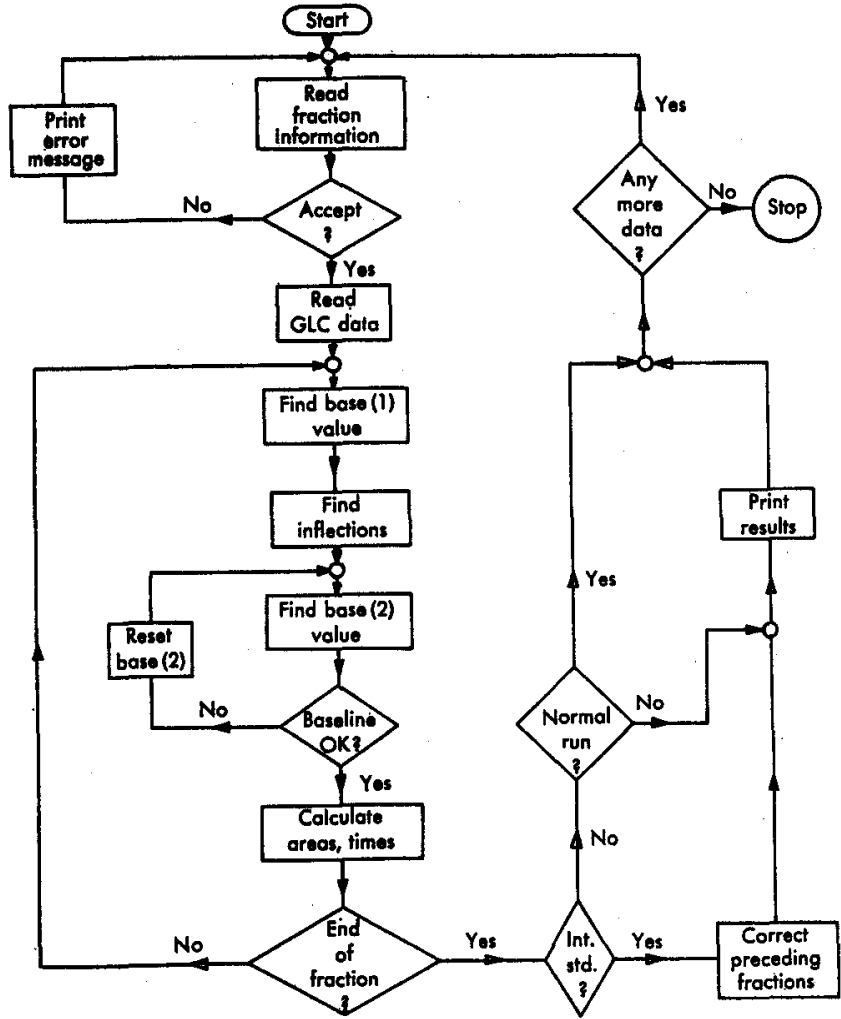

This will include the date, fraction number and attenuation, the sample and run numbers, and the parameter values to be used by the program.

The input routine reads the fraction information, and examines this to ensure that there are no obvious errors - e. g. that there are the correct number of items of information, and that each has a value within reasonable limits. If any mistake in the manual punching is discovered, an error message is printed out, and the corresponding fraction data is not processed: the program goes on to the next fraction. When the fraction information is acceptable, the digital GLC data is then read in, until a (manually punched) terminator value $(99,999)$ is found. At this point, the data is passed to the area measurement routine.

\section{Area Measurement}

Peak areas are measured in groups, starting and ending on baseline. The chromatogram starts on baseline, by definition, and the start of the first peak is then defined by the values of two parameters, $\mathrm{N}$ and S. Peak detection occurs when $\mathrm{N}$ successive first differences have a total value $>$. . The peak start point is taken as one data point before the first of the $(N+1)$ data points involved. The baseline value before this peak is calculated as the mean of the three preceding data points. Values of $\mathrm{N}$ and $\mathrm{S}$ are set, to allow easy distinction between noise, and true peaks. The maximum noise level is 3 counts ( $=0.03 \% \mathrm{FSD}$ ), calculated as twice the standard deviation.

Having found the first peak, the program examines the subsequent data for inflection points, using the first and second differences (8) to find peak maxima, and shoulders. A third parameter, INF, is used here to allow adequate detection of shoulders, without trouble from any noise present: INF sets the absolute value, by which the second difference must change during the first, or second half of a peak before a leading, or trailing, shoulder is detected.

The end of any peak is defined as the last data point on the trailing edge, before an increase in value of the data occurs. An examination of subsequent points is made, to determine whether the peak ended on baseline, or in a valley between two peaks. The valley condition is determined by the parameters $\mathrm{N}$ and $\mathrm{S}$ : an increase during the five data points after peak end of more than N/S is taken to indicate a valley. This is a less stringent condition than that for the detection of a peak, starting from baseline, and prevents small peaks on the tail ends of larger peaks from being missed.

When a second baseline condition has been reached, a mean baseline value is again calculated, and the position of the line joining the two baseline points is tested, to ensure that none of the intermediate data points fall below this line. If they do, the second baseline position is moved forward to an earlier valley position where the above criterion is satisfied. This prevents errors being caused by groups of partially resolved small peaks, which may form a "plateau" which is flat enough to resemble baseline; and also prevents incorrect (or negative) area measurements where a series of joined peaks occurs on top of a steep baseline drift.

When a pair of baseline positions have been established, the area of each peak between them is calculated, by addition of the appropriate data points, and deduction of the trapezoidal baseline area beneath the peak. The area, together with retention time and other characteristics, is then stored until all calculations on the fraction have been done. The program continues from the last baseline position, repeating the above procedure for the rest of the data.

This method allows quite economical use of the computer store, as the processing normally involves only a part of the data at any given time. A further advantage is that it would be possible to "switch in" other measurement routines as required, e.g. curve resolution $(9,10)$, to deal with particular parts of a chromatogram.

\section{Internal Standard Correction}

Four or five of the fractions on a normal tape will be internal standard peaks: these are trapped as the last fractions in each run on the primary column, and all peak areas in the $(3$ or 4$)$ fractions from the same primary run (i. e. the same injection) are corrected by the corresponding internal standard peak area, and the fraction attenuation, so that all peak areas are finally expressed as ratios to the internal standard area, at constant attenuation. This allows for variations in injection size, detector sensitivity and the individual attenuations used for each fraction. Calibration standards are treated in exactly the same way. The internal standard substance is di-n-butyl phthalate, added in 
Figure 4. Typical fraction printout.

Fraction no. 16, sample no. 62 , run no. 1 Internal standard $=100197$

\begin{tabular}{|c|c|c|c|c|c|c|}
\hline Peak no. & $\begin{array}{l}\text { Charac- } \\
\text { teristics }\end{array}$ & Start & End & Retention & Area & $\begin{array}{c}\text { Corrected } \\
\text { area }\end{array}$ \\
\hline 1 & B T & 36 & 44 & 42 & 763.0 & 8 \\
\hline 2 & TT & 46 & 66 & 50 & 16414.1 & 164 \\
\hline 3 & $T T$ & 68 & 80 & 72 & 819.3 & 8 \\
\hline 4 & $T T$ & 82 & 92 & 84 & 248.4 & 2 \\
\hline 5 & $\mathrm{TT}$ & 94 & 116 & 108 & 1135.0 & 11 \\
\hline 6 & TT & 118 & 128 & 120 & 235.7 & 2 \\
\hline 7 & TU & 130 & 144 & 136 & 831.0 & 8 \\
\hline 8 & UD & 146 & 170 & 152 & 32349.0 & 323 \\
\hline 9 & DT & 172 & 180 & 178 & 2562.4 & 26 \\
\hline 10 & T T & 182 & 206 & 190 & 29511.9 & 295 \\
\hline 11 & $T T$ & 208 & 226 & 214 & 6981.0 & 70 \\
\hline 12 & $T T$ & 228 & 238 & 230 & 1982.0 & 20 \\
\hline 13 & TT & 240 & 274 & 254 & 9594.7 & 96 \\
\hline 14 & $\mathrm{TT}$ & 276 & 312 & 292 & 5413.0 & 54 \\
\hline 15 & $T T$ & 314 & 348 & 326 & 4363.8 & 44 \\
\hline 16 & T T & 350 & 376 & 364 & 2774.0 & 28 \\
\hline 17 & TB & 378 & 406 & 380 & 760.9 & 8 \\
\hline 18 & B T & 448 & 486 & 458 & 798.8 & 8 \\
\hline 19 & $T T$ & 488 & 508 & 498 & 360.7 & 4 \\
\hline 20 & TD & 510 & 536 & 526 & 1134.1 & 11 \\
\hline 21 & D B & 538 & 570 & 546 & 488.9 & 5 \\
\hline 22 & B T & 576 & 602 & 590 & 2181.7 & 22 \\
\hline 23 & TB & 604 & 632 & 612 & 1862.0 & 19. \\
\hline \multicolumn{7}{|c|}{ End of data -23 peaks } \\
\hline
\end{tabular}

Attenuation $=2000$

$\operatorname{lnf}=5$

$N$

$0.50 \% \mathrm{w} / \mathrm{v}$ concentration to the acetone used to dissolve the smoke "semi-volatiles".

The fraction and run numbers are used to distinguish between experimental runs without internal standards, normal runs, and internal standard fractions. Internal standards have the fraction number punched as 99; experimental fractions are given run number $=0$, and the results are printed as "uncorrected", as soon as the areas etc. have been calculated. Normal fractions are processed, and the results stored, until an internal standard fraction is found. Then the peak areas in the preceding fractions are corrected, and the results for these fractions, and the internal standard for the run, are printed out.

\section{Output}

Fig. 4 shows the printout of one fraction from the computer. The times are in seconds, and the characteristics shown refer to the conditions at the start and end of each peak: $B$ for baseline, $T$ for trough (valley), $\mathrm{U}$ and $\mathrm{D}$ for up (leading) and down (trailing) shoulders.

A graphical output can also be obtained, by using a version of the program containing plotting instructions. Fig. 5 shows the graph plotter output corresponding to the printout in Fig. 4. The "chromatogram" is a plot of the data points for this fraction, and it can be seen that the data resolution is quite adequate. Comparison with the original chart recorder trace shows no loss of information; in fact, the digital version reveals small variations which are below the response capabilities of the chart recorder.

The baselines and peak separators found by the program have also been plotted, together with the peak numbers. Baseline drift has occurred to some extent, and peak areas have been corrected for this. This type of output has proved to be very useful for experimental purposes, during program development, and in finding the correct parameter values.

Figure 5. Graph plotter output corresponding to Fig. 4.

Fraction no. 16, sample no. 62

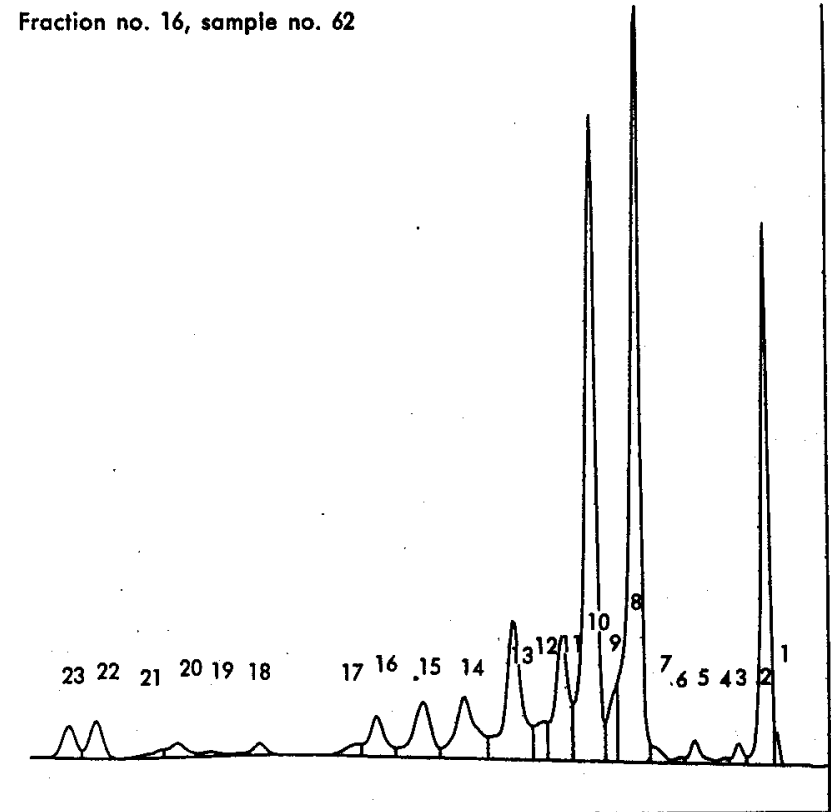


Figure 6. Comparative eigarette smoke yields.

(see text for compound names)

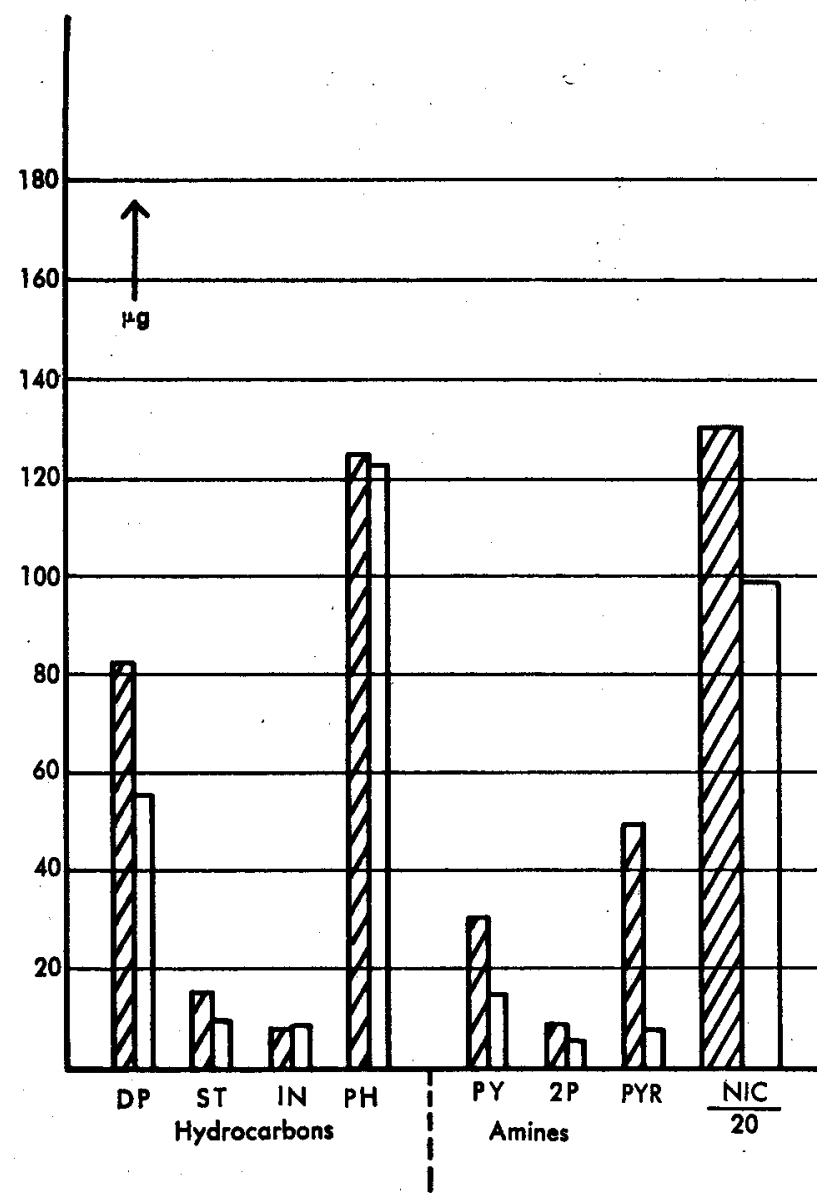

Yields per cigarette

Length: $70 \mathrm{~mm}$

Butts : $23 \mathrm{~mm}$
Z Burley

U.K. blend

Figure 7.

Selectivity: $15 \mathrm{~mm}$ acetate
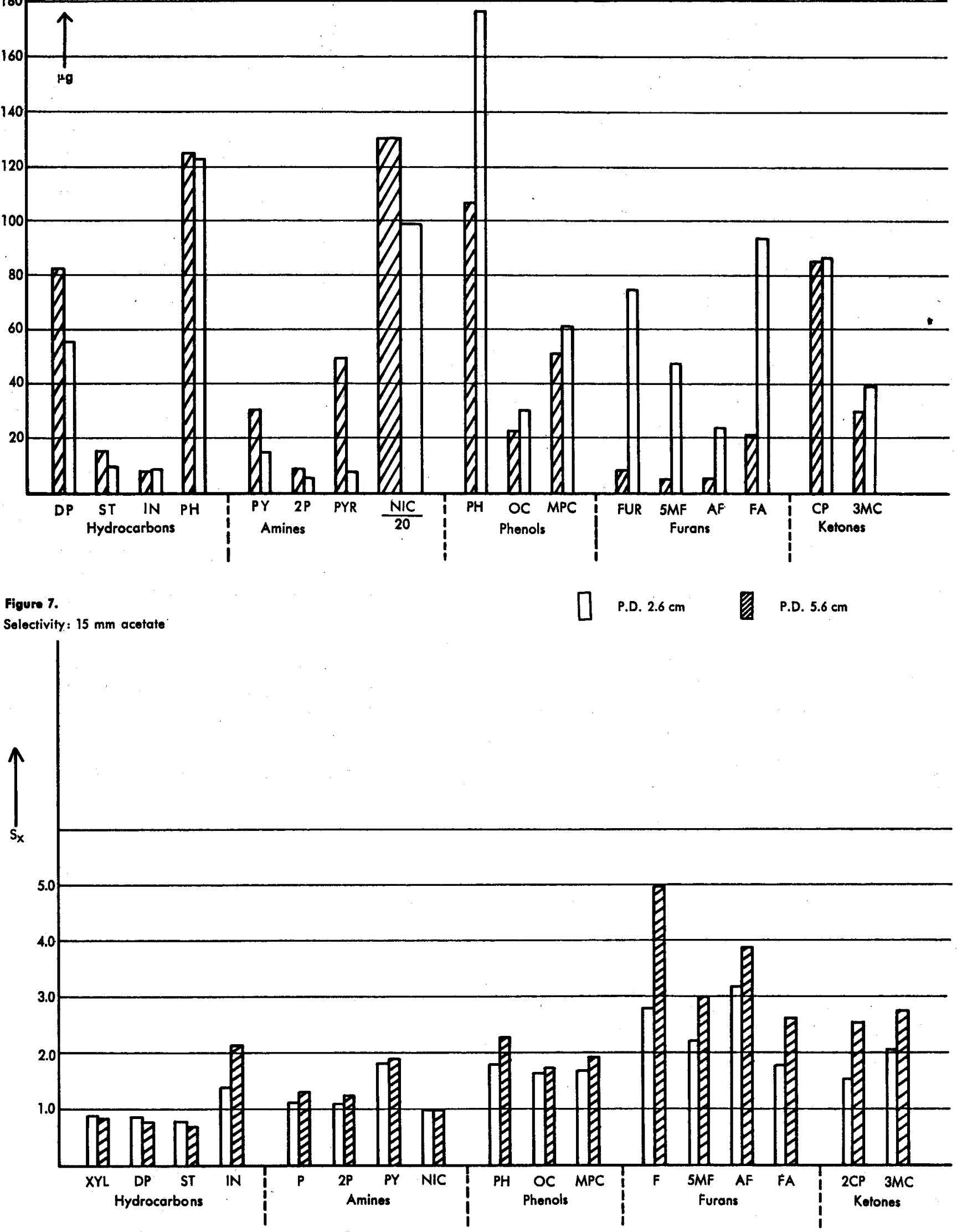
Fig. 6 shows the yields, in $\mu \mathrm{g} /$ cigarette, of a selection of "semi-volatile" compounds, from two different tobacco types. The cigarettes were $70 \mathrm{~mm}$ long, smoked to $23 \mathrm{~mm}$ butts, using "open" smoking. One cigarette was made from uncased Burley tobacco; the other was an English commercial blend cigarette, mainly flue-cured tobacco.

The compounds have been divided into classes, with a few compounds included in each class. The hydrocarbons are dipentene (DP), styrene (ST), indene (IN) and neophytadiene (PH). In the case of neophytadiene, the calibration was done by using nonadecane, and assuming equal response factors for the two compounds (11). The main difference here between the two smokes is that the Burley has yielded more dipentene $82 . \mu \mathrm{g} / \mathrm{cigarette}$ as against $56 \mu \mathrm{g} / \mathrm{cigarette}$ for the fluecured tobacco. The other hydrocarbons give fairly similar yields in each smoke.

The amines are pyridine (PY), 2-picoline (2P), pyrrole (PYR), and nicotine (NIC). The nicotine values have been scaled down by a factor of 20 , so that the relative yields could be included in this presentation. In each case, the Burley cigarette has yielded more of these compounds, about six times as much in the case of pyrrole; the nicotine yields were $2.60 \mathrm{mg} /$ cigarette and $1.97 \mathrm{mg} /$ cigarette respectively for the Burley and fluecured cigarettes.

The next class, phenols, are phenol $(\mathrm{PH})$, o-cresol $(\mathrm{OC})$, and $(\mathrm{m}+\mathrm{p})$-cresols (MPC). Here, in contrast to the amines, the flue-cured cigarette produced higher yields: considerably more in the case of phenol - $177 \mu \mathrm{g} / \mathrm{ciga-}$ rette against $107 \mu \mathrm{g} /$ cigarette for the Burley cigarette.

The furan derivatives are furfural (F), 5-methylfurfural (5MF), acetyl furan (AF), and furfuryl alcohol (FA). Here again, the flue-cured cigarette yields more of each compound, and the increases are quite considerable up to 8 or 9 times the amounts in the Burley smoke.

The final group comprises two cyclic ketones, 2-cyclopenten-1-one (2CP) ( 1 ), and a methyl derivative of this ketone, which we have tentatively identified as 3-methyl-2-cyclopenten-1-one (3MC). The yields are quite similar in the two smokes.

Thus the major differences which are shown between the two cigarette smokes are that the alkaline, Burley smoke contains considerably more of the volatile amines and nicotine; the acidic, flue-cured smoke contains considerably more phenol, more of the cresols, and very much more of the furan derivatives. Some of these differences can be explained fairly readily: e. g. the furans are known to be predominant pyrolysis products of sugars, and the Burley tobacco contains virtually no sugar. Again, the volatile amines are pyrolysis products of nicotine, and with more nicotine in the Burley smoke, we can expect more of its pyrolysis products.

The following results (Figs. $7-9$ ) all deal with the selectivity of filters. There has been some discussion about selectivity, and how it should be measured, in the last few years (12); the examples given here have been calculated according to the formula of Davis and George (13). This relates the relative yields of a reference substance and the compound to be considered, in filtered and unfiltered smoke. Davis and George used total smoke condensate as their reference, but the results presented here were calculated using neophytadiene as the reference. This seems to be more satisfactory, in as much as it is a defined compound, a high boiling point hydrocarbon, of low polarity: it would therefore, be subject to mechanical filtration only. It is present in the tobacco, and not formed by pyrolysis; and finally, the relatively large amount in cigarette smoke made it comparatively easy to measure in this work.

Fig. 7 shows selectivity values (Sx), calculated in this way for two acetate filters, each $15 \mathrm{~mm}$ long, with P.D.'s of 2.6 and $5.6 \mathrm{~cm}$ water respectively. The filters were fitted to $55 \mathrm{~mm}$ U.K. blend tobacco rods, cut from $70 \mathrm{~mm}$ plain cigarettes, giving a total tipped cigarette length of $70 \mathrm{~mm}$. The $70 \mathrm{~mm}$ untipped cigarettes were used as controls for the selectivity calculations. All cigarettes were smoked to total butt lengths of $23 \mathrm{~mm}$, using the Coresta standard cycle. Sx values have been calculated for each filter, for the same compounds as in Fig. 6, with the addition of o-xylene (XYL): neophytadiene, as the reference compound $(5 x=1.0)$ has been omitted.

It is seen that, in general, the values are greater than 1.0, and tend to increase with increase in P.D., i. e. the acetate filter is a selective filter. In the case of the first three hydrocarbons (o-xylene, dipentene, styrene) the Sx values are just below 1.0, and decrease slightly with increased filter P.D. This is presumably because these compounds show little or no affinity for cellulose acetate, and being quite volatile compounds, their filtration is not as much affected by increase in P.D. as is that of the reference compound. The other hydrocarbon, indene, is a reactive compound, and shows a fairly strong selective effect.

The volatile amines (pyridine, 2-picoline, pyrrole) all show some selective effect. This is not dependent on basicity, and the largest $S x$ value is given with pyrrole. Nicotine, as this is acidic smoke, shows no selective effect at all, because it will be present in the smoke as non-volatile salts, and therefore, subject to mechanical filtration only.

The phenols show selective filtration effects with acetate filters, as has often been reported (12). An increase in the selectivity values is shown with increased filter P.D. The Sx value for phenol, the most volatile of this group, is higher than those for the cresols.

The furans, and the cyclic ketones, show some of the largest selectivity effects with the acetate filters, each one increasing with increase in filter P.D. These are all fairly volatile, polar compounds, some with two oxygen atoms per molecule. They are, therefore, available for selective action, and capable of forming hydrogen bonds fairly readily, which is presumably one of the main reasons for the selectivity of cellulose acetate.

Fig. 8 shows, on the same scale, $S x$ values for the same compounds as in Fig. 7 , with two paper filters. 


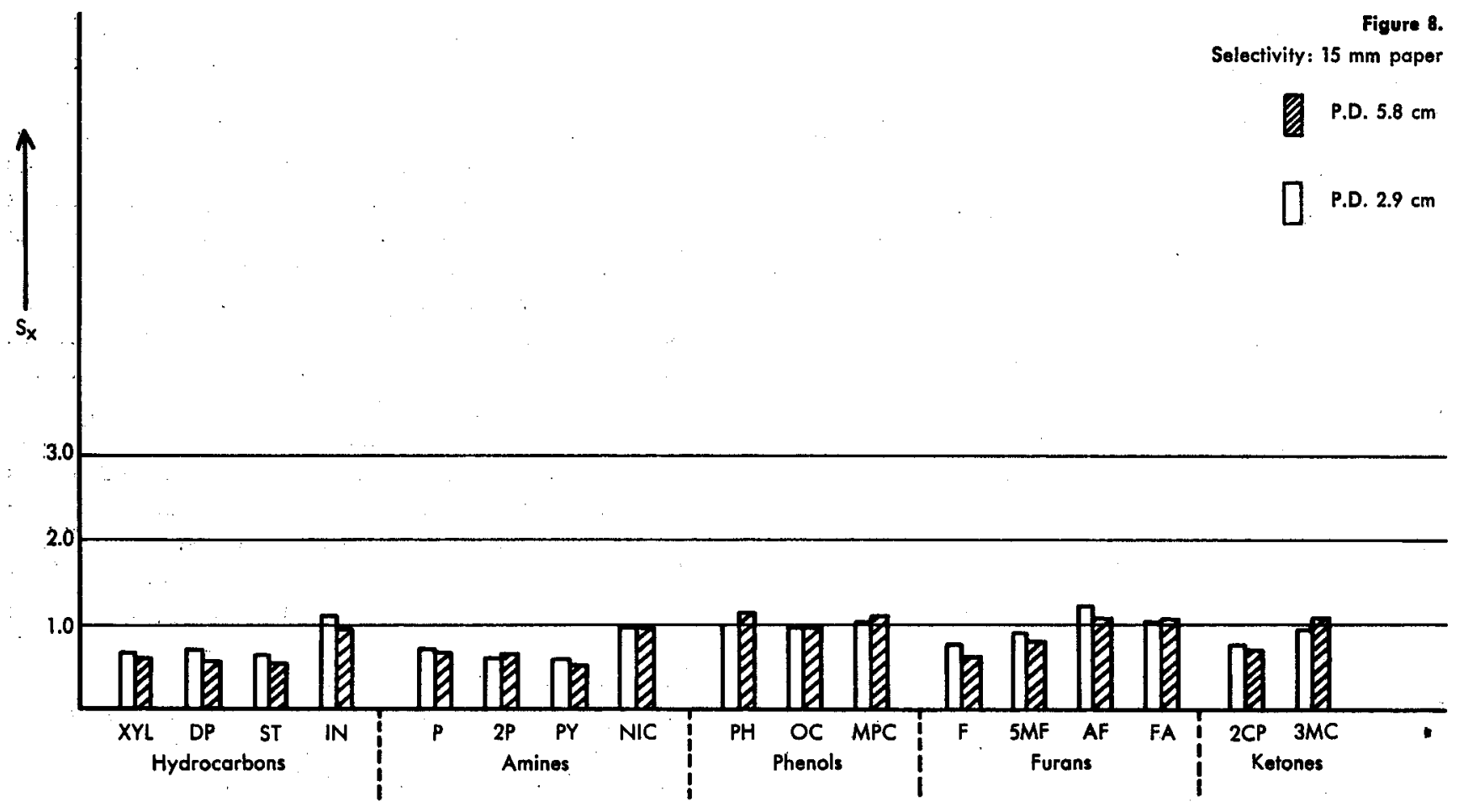

Each was $15 \mathrm{~mm}$ long, and the P.D.'s were 2.9 and $5.8 \mathrm{cms}$ water, respectively. The cigarette and smoking parameters are the same as those in the previous example.

The paper filter is seen to be non-selective: many of the $S x$ values, especially for the higher boiling point compounds, are close to 1.0, and the tendency is for a decrease in selectivity with increase in filter P.D. The more volatile compounds show, generally, values of less than 1.0, showing that their filtration is relatively less efficient than that of the mechanically filtered reference compound. Increase in filter P.D. makes this difference slightly greater. This result is similar to that obtained for the volatile non-polar compounds with the acetate filters, and indicates the lack of affinity of any of these volatile compounds for the paper filter.

The smoke was acidic, as before, so that nicotine, present as salts, gives $5 x$ values very close to 1.0 as in the acetate filters.

The phenols show values close to 1.0, with a slight tendency to increase with increased P.D., which may indicate some small selective action.

The selectivity values, as such, do not reveal anything about the retention of the filter, and in fact, the retention per unit P.D. of the paper filter is higher than with acetate: the two paper filters in Fig. 8 had higher neophytadiene and nicotine retentions than the corresponding acetate filters of similar P.D. in Fig. 7 .

Fig. 9 illustrates the use of selectivity measurements with a filter additive. This was done by preparing tipped cigarettes with two similar paper filters, each $15 \mathrm{~mm}$ long: one was treated with tartaric acid, the other untreated. The control in this case was the cigarette with untreated filter, so that selectivity effects refer to the additive only. The tobacco rods were of a type made from cigar tobacco, giving strongly alkaline smoke.

The acidic filter has obviously had a considerable effect on the amines, as would be expected. The other Sx values are, in general, quite close to 1.0, showing that there is no drastic effect on most of the other compounds by the additive. The exception is furfural, where the Sx value is only 0.3: this indicates a definite increase in the amount of furfural present in the smoke passing the additive-treated filter. This was, in fact, only a very small weight increase, because the smoke of these cigarettes contains only a few $\mu \mathrm{g}$ of furfural - but it is of interest, because of the possibility that the reason for this low $S x$ value may be that the acidity of the filter has prevented some reaction which normally takes place with furfural in alkaline tar conditions.

However, the main effect of the additive is on the amines, and the $S x$ values shown increase in the same order as basic strength for the volatile compounds: 2-picoline, the strongest base, having the highest $S x$ value. Nicotine also shows a selective action $(S x=1.25)$. Although nicotine is a comparatively strong base, this value is lower than the others because of the much lower volatility of nicotine. In fact, however, even this relatively small value indicates the selective removal of a fairly large amount of nicotine per cigarette.

The FTTD-computer system was developed to provide smoke "semi-volatiles" analyses, in considerably greater detail than had previously been available to us. It was decided, at the beginning of this work, that an attempt to obtain reliable measurements on all compounds present would involve enormous effort. The purpose has been, instead, to obtain valid 


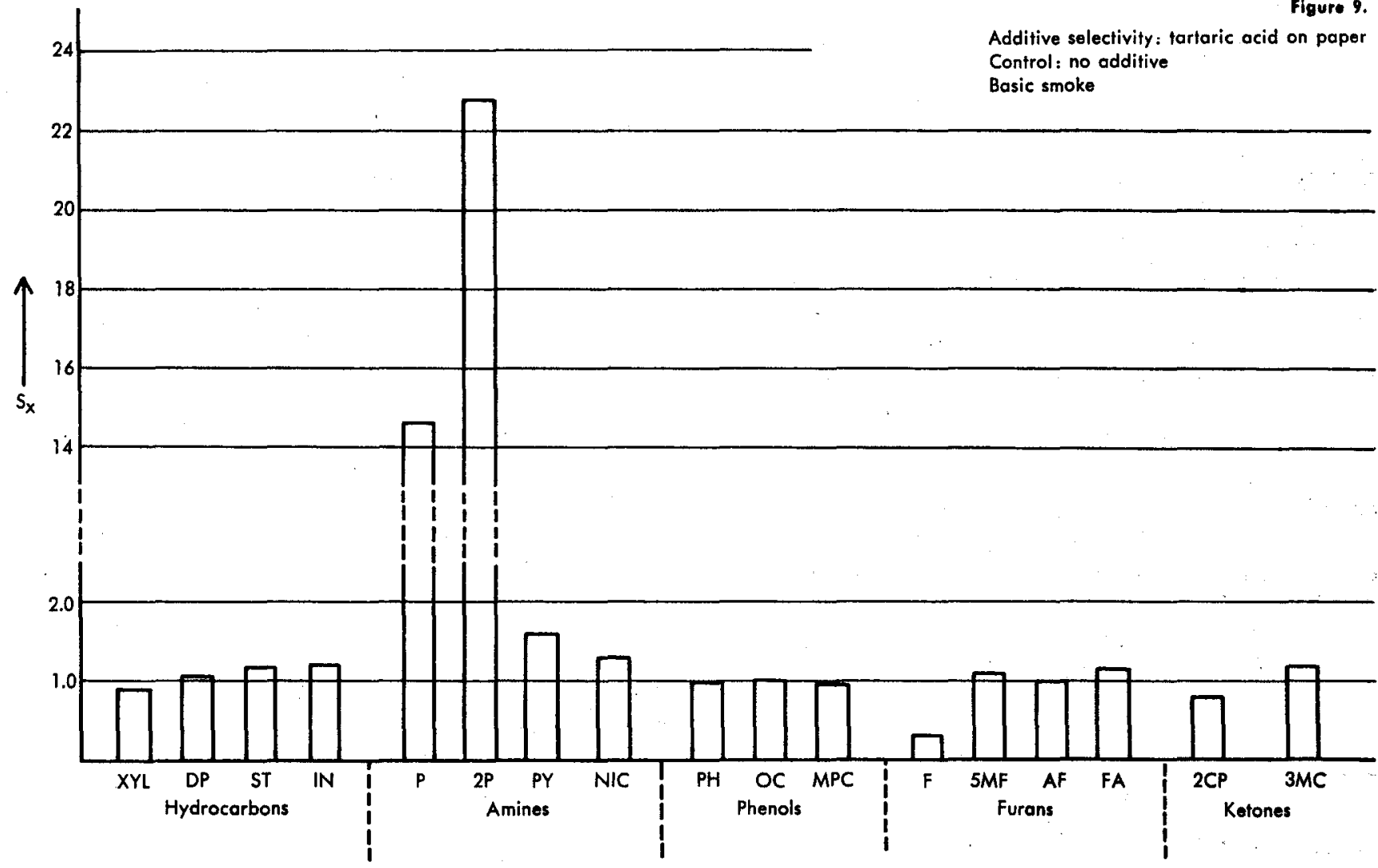

quantitative data on as many of the compounds as possible, including those still to be identified, which are present in the smoke to the extent of at least I $\mu \mathrm{g} /$ cigarette.

Variations in these peak areas are at present in the range $5-20 \%$ for single analyses, using 5-cigarette samples. All results reported here are mean values of at least 4-channel analyses. Measurements of the GLC-computer system reproducibility (1) indicate that a large part of the overall variation is due to the smoke preparation process: this is currently being revised to include larger cigarette samples, and the direct injection of whole smoke solutions.

The correlation of peak identities between different analyses is at present done by comparison of the computer print-outs, and the corresponding recorder charts of the fractions. This is a tedious, but not difficult, task, because retention time variations are quite small $(1-2 \%)$, despite the use of fast temperature programming. This is due to the automatic nature of the injection on to the FTTD secondary column. The computer program is now being expanded to include a correlation routine, so that results from related analyses (e.g. filter and non-filter cigarette) can be produced in correlated form, on punched cards. These cards will then be processed by computer to give comparative results, such as selectivity or retention values. At present, the final results are obtained from manually correlated area values by the use of a time-sharing terminal (Time Sharing Ltd., London). A program written in Telcomp 2 for this purpose, produces the results in tabular and histogram form.

\section{SUMMARY}

A two-stage GLC system has been developed to produce a separation of cigarette smoke "semivolatiles" into several hundred peaks per analysis. Quantitative measurements of the separated peak areas, with correction for baseline drift and an internal standard value, are made by an off-line computer, using a digital output obtained from the GLC system on punched tape. The main features of the computer program used are described, and typical output data are shown. Results of analyses dealing with cigarette smoke composition, and the selective effect of various filters, are presented. The use of neophytadiene as reference compound for the selectivity calculations is described.

\section{ZUSAMMENFASSUNG}

Ein zweistufiges Gaschromatographiesystem wurde entwickelt, um die "semi-volatiles" des Cigarettenrauches in mehrere hundert Peaks aufzutrennen. Quantitative Messungen der Flächen der getrennten Peaks unter Berücksichtigung des Basisliniendrifts und der Größe eines internen Standards wurden mit einem Computer in off-line Anordnung gemacht. Die digitale Ausgabe vom gaschromatographischen System erfolgte über Lochstreifen. Die Hauptpunkte des benutzten Computerprogramms werden beschrieben, typische Ausgabedaten werden gezeigt. Ergebnisse von Analysen der Cigarettenrauchzusammensetzung und von Messungen der selektiven Wirkung verschiedener Filter werden mitge- 
teilt. Der Gebrauch von Neophytadien als Vergleichssubstanz für Selektivitätsberechnungen wird beschrieben.

\section{RESUME}

Un système GLC à deux plateaux a été mis au point pour permettre une séparation en plusieurs centaines de pics des matières semi-volatiles de la fumée de cigarettes. La mesure quantitative de la surface des pics séparés est obtenue par un ordinateur non raccordé, après correction de la ligne de base. Un étalon interne est utilisé. L'information du système GLC est recueillie sur bande perforée et transmise ainsi à l'ordinateur. Le schéma de base du programme d'ordinateur est décrit, et des exemples de résultats expérimentaux sont montrés. Les résultats d'analyse des fumées de cigarette et l'effet sélectif de différents filtres sont exposés. On décrit l'emploi du néophytadiène comme étalon pour les calculs de sélectivité.

\section{REFERENCES}

1. Graham, J. F.: Beitr. Tabakforsch. 5 (1969) 43.

2. Baumann, F., and Tao, F.: J. Gas Chrom. $5(1967) 621$.

3. McCullough, R. D.: ibid. 5 (1967) 635.
4. Jones, K., McDougall, A. O., and Marshall, R. C.: "Gas Chromatography 1966", A. B. Littlewood, Ed., Institute of Petroleum, London 1967, p. 376.

5. Dymond, H. F., and Kilburn, K. D.: ibid., p. 353.

6. Johnson, H. W.: Anal. Chem. 35 (1963) 521.

7. Schofield, C. F.: "Manual of the Atlas Fortran V Language", University of London Atlas Computing Service, 1967.

8. Savitzky, A.: Anal. Chem. 33 (1961) 25A.

9. Bartlet, J. C., and Smith, D. M.: Canad. J. Chem. 38 (1960) 2057.

10. Westerberg, A. W.: Anal. Chem. 41 (1969) 1770.

11. Ettre, L. S.: J. Chromatog. 8 (1962) 525.

12. George, T. W., and Keith, C. H.: in "Tobacco and Tobacco Smoke" by Wynder, E. L., and Hoffmann, D., Academic Press Inc., London, pp. 577-622, 1967.

13. Davis, H. J., and George, W. T.: Beitr. Tabakforsch. 3 (1965) 203.

\section{Acknowledgement}

I wish to thank D. P. Clay for his capable assistance in the experimental work.

The author's address:

Cigarette Components Ltd.,

Research and Instrument Department, 30/31 Abbey Estate, Mount Pleasant, Alperton, Wembley, Middlesex, England. 